\title{
Interstitial pneumonitis secondary to azathioprine in a renal transplant patient
}

\author{
DJS CARMICHAEL, DV HAMILTON, DB EVANS, PGI STOVIN, RY CALNE \\ From Addenbrooke's Hospital, Hills Road, Cambridge
}

Several cytotoxic agents have been reported to cause lung damage, the commonest being bleomycin, busulphan, and methotrexate. ' We wish to report the occurrence of interstitial pneumonitis in a patient with a cadaveric renal and pancreatic allograft receiving prednisolone and azathioprine as immunosuppressive treatment.

\section{Case report}

A 38 year old woman was admitted on 1 January 1981 with a five day history of night sweats and rigors associated with fever. She had been an insulin dependent diabetic from the age of 10 years and commenced chronic intermittent haemodialysis in January 1980 because of end stage diabetic nephropathy. She had developed diabetic retinopathy 10 years previously. This had been treated by vitrectomy on the right and photocoagulation in both eyes.

In April 1980 she received a pancreatic and renal allograft and was immunosuppressed with cyclosporin A. She required insulin for six hours postoperatively. She was readmitted on 8 August 1980 with a serum creatinine concentration of $452 \mu \mathrm{mol} / 1(5 \cdot 1 \mathrm{mg} / 100 \mathrm{ml})$, which had risen from a level of $173 \mu \mathrm{mol} / \mathrm{l}(2.0 \mathrm{mg} / 100 \mathrm{ml})$ recorded on 13 July. A renal biopsy specimen showed appearances of severe rejection and she was treated with methylprednisolone (1 $\mathrm{g}$ daily intravenously for three days). Her renal function continued to deteriorate (serum creatinine $840 \mu \mathrm{mol} / \mathrm{l}(9.5 \mathrm{mg} / 100 \mathrm{ml})$ and a further biopsy specimen on 2 September again showed appearances of rejection. Her treatment was changed to prednisolone (75 $\mathrm{mg} /$ day $)$ and azathioprine $(1.5 \mathrm{mg} / \mathrm{kg}=75 \mathrm{mg} /$ day $)$. Her renal function improved (serum creatinine $216 \mu \mathrm{mol} / \mathrm{l}(2.4$ $\mathrm{mg} / 100 \mathrm{ml}$ ) and the dose of corticosteroid was accordingly reduced. She required insulin as a result of deterioration in glucose tolerance secondary to corticosteroid treatment. At the time of her admission at the beginning of 1981 she was receiving prednisolone $17.5 \mathrm{mg} /$ day and azathioprine $50 \mathrm{mg} /$ day (reduced because of leucopenia).

Address for reprint requests: Dr DJS Carmichael, St Mary's Hospital, London W2 1 PG.

Accepted 6 June 1983
On admission on 1 January 1981 she had extensive perioral herpes simplex and a swinging fever, rising at its height to $40^{\circ} \mathrm{C}$. Investigations showed a serum creatinine concentration of $215 \mu \mathrm{mol} / \mathrm{l}(2.4 \mathrm{mg} / 100 \mathrm{ml})$, haemoglobin $9.9 \mathrm{~g} / \mathrm{dl}$, white cell count $2.3 \times 10^{9} / 1$ (eosinophils $0 \cdot 1 \times 10^{9} / 1$ ), and platelets $272 \times 10^{9} / 1$. The chest radiograph was normal; blood, urine, and sputum cultures were negative. Paired sera for rising antibody titres to influenza virus A and B, cytomegalovirus, adenovirus, Coxiella burnetii, Mycoplasma pneumoniae, and Chlamydia psittaci showed no evidence of infection with these agents. Despite negative bacterial cultures the patient was started on flucloxacillin and amikacin. After six days' treatment there was no improvement and she was treated with acyclovir (225 $\mathrm{mg}$ three times a day) for three days. Her pyrexia continued and she became progressively dyspnoeic with the development of basal crepitations. Successive chest radiographs showed the gradual appearance of bilateral diffuse shadowing of nodular type. The arterial oxygen tension was $9.9 \mathrm{kPa}(74 \mathrm{~mm} \mathrm{Hg})$; lung function studies showed a restrictive defect with appreciable decrease in carbon monoxide transfer factor (table). On 20 January a drill biopsy of her left lung was performed. Histological examination showed mild interstitial infiltration, mainly with lymphocytes and plasma cells, and some early alveolar wall fibrosis. The alveoli were patchily but extensively

Results of pulmonary function tests

\begin{tabular}{|c|c|c|c|c|}
\hline & \multicolumn{2}{|c|}{30 January } & \multicolumn{2}{|l|}{18 March } \\
\hline & Observed & $\begin{array}{l}\% \\
\text { predicted }\end{array}$ & Observed & $\begin{array}{l}\% \\
\text { predicted }\end{array}$ \\
\hline \multirow{4}{*}{ 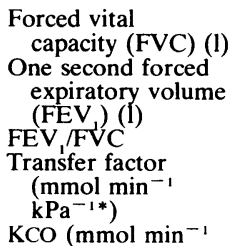 } & $2 \cdot 55$ & 73 & $2 \cdot 55$ & 73 \\
\hline & $\begin{array}{l}2.15 \\
0.84\end{array}$ & 76 & $\begin{array}{l}2.50 \\
0.87\end{array}$ & 87 \\
\hline & & & & \\
\hline & $3 \cdot 21$ & 39 & $5 \cdot 37$ & 60 \\
\hline $\left.\mathrm{kPa}^{-1 *}\right)$ & $1 \cdot 12$ & 62 & $1 \cdot 14$ & 78 \\
\hline
\end{tabular}

${ }^{*}$ Corrected for anaemia. 


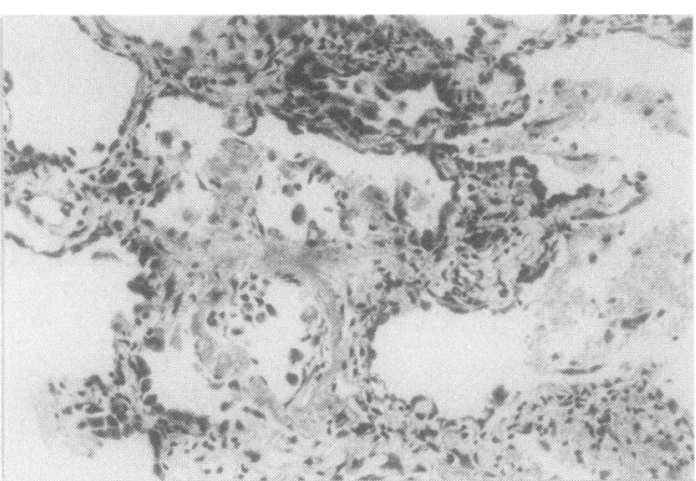

Lung biopsy specimen showing fibrous thickening of alveolar walls with intra-alveolar granular fibrinous exudate with swelling of cells lining alveoli and some intra-alveolar desquamation. (Haematoxylin and eosin, $\times 145$.)

filled with fibrin, and intact and degenerative alveolar lining cells (fig). The presence of intra-alveolar fibrin was suggestive of damage to the alveolar capillaries, but no electron microscopic studies were made on the biopsy specimen. Histologically Gram, Ziehl Neelsen, Grocott, and periodic acid Schiff stains were used; the results were negative for bacterial, fungal, and parasitic infections. Fluid obtained at the time of the biopsy was sent for bacterial (including acid fast bacilli) and fungal culture, and all cultures were negative. Immunoperoxidase staining failed to show any IgA, IgM, or C3 deposition in the vascular or alveolar wall basement membranes.

Azathioprine was discontinued on 28 January; the patient's dyspnoea improved over the next eight days and her temperature became normal after six days. Two months later her chest radiograph was normal and her carbon monoxide transfer factor had improved (table). Immunosuppression was maintained with prednisolone (10 $\mathrm{mg} /$ day) and cyclosporin A. Unfortunately there has been a gradual deterioration in her renal function and the plasma creatinine concentration in February 1983 was 750 $\mu \mathrm{mol} / \mathrm{l}(8.5 \mathrm{mg} / 100 \mathrm{ml})$. She has no respiratory symptoms and a normal chest radiograph.

\section{Discussion}

The diagnosis of lung damage secondary to cytotoxic drugs depends on three factors: a history of drug exposure, a demonstration of lung damage, and exclusion of other causes of lung damage. ${ }^{1}$ In the present case all three criteria have been fulfilled.
In reports published in English azathioprine induced interstitial pneumonitis has been reported in two patients. Rubin $e a^{2}{ }^{2}$ report the development of an acute restrictive pulmonary disease in a 20 year old man with ulcerative colitis after treatment with azathioprine $(100 \mathrm{mg} /$ day $)$ for six weeks. He complained of a dry cough, rapidly increasing exertional dyspnoea, and fever. The chest radiograph showed bilateral basal shadowing and respiratory function tests showed severe reduction in vital capacity, $\mathrm{FEV}_{1}$, and carbon monoxide gas transfer. Two days after discontinuation of azathioprine his chest radiograph and results of respiratory function tests were normal. Lung biopsy was not performed. Weisenberger ${ }^{3}$ describes an acute interstitial pneumonitis in a 24 year old woman with rapidly progressive renal failure secondary to membranoproliferative glomerulonephritis who was treated with azathioprine (150 mg/day) for two years. She developed fever, dry cough, and shortness of breath. Serial chest radiographs showed progressive pulmonary infiltrates and there was reduction in arterial oxygen tension. Open lung biopsy showed an acute interstitial pneumonitis; hyperplasia of type 2 pneumocytes was prominent. Within a week of her stopping azathioprine the patient's symptoms had improved and within two weeks they had resolved and the chest radiograph was normal.

Azathioprine is metabolised to 6-mercaptopurine, which has also been incriminated in interstitial pneumonitis; Sostman et $\mathrm{al}^{4}$ report the development of interstitial pneumonitis, confirmed by lung biopsy, in a two year old boy with leukaemia after three days' treatment with 6-mercaptopurine.

This is the first reported case of interstitial pneumonitis in a renal transplant recipient despite the extensive use of azathioprine in these patients. Drug induced interstitial pneumonitis can be misdiagnosed as an opportunistic infection. Cyclosporin $A$ provides an alternative immunosuppressive agent in patients who develop this complication after transplantation.

We wish to thank Mr C Burton for photographic help and Mr R Kingshot for technical assistance.

\section{References}

' Collis CH. Lung damage from cytotoxic drugs. Cancer Chemother Pharmacol 1980;4:17-27.

${ }^{2}$ Rubin G, Baume R, Vandenberg R. Azathioprine and acute restrictive lung disease. Aust $N Z J$ Med 1972;3:272-4.

${ }^{3}$ Weisenberger DD. Interstitial pneumonitis associated with azathioprine therapy. Am J Clin Pathol 1978;69:181-5.

4 Sostman HD, Matthay RA, Putnam CE. Cytotoxic drug induced lung disease. Am J Med 1977;62:608-15. 